\title{
Coronary and peripheral arterial responses to ergometrine in patients susceptible to coronary and oesophageal spasm
}

\author{
J J DALAL, A M DART, H ALBAN DAVIES, D J SHERIDAN, \\ M S T RUTTLEY, A H HENDERSON \\ From the Department of Cardiology, Welsh National School of Medicine, Cardiff
}

SUMMARY Vascular responses to ergometrine were compared in groups of patients subject to coronary artery spasm, or oesophageal spasm, or neither. We measured the degree of diffuse narrowing at different coronary artery sites (not in spasm), and the rise in blood pressure. The data provide no evidence for a generalised sensitivity to alpha-adrenergic stimulation underlying either of these two clinical entities. The left main stem was narrowed significantly less than the three main branches of the coronary artery tree. The degree of diffuse coronary artery narrowing was not influenced by the presence or absence of minor $(\leqslant 50 \%$ ) fixed stenotic lesions, nor by the initial calibre of the arteries. Ergometrine did not alter arterial lactate concentration or lactate extraction in the absence of coronary spasm.

Why certain patients develop susceptibility to coronary artery spasm is unknown. Similarly unexplained is why some patients experience intermittent oesophageal spasm in the absence of reflux oesophagitis. ${ }^{1}$ Both phenomena reflect smooth muscle contraction, mediated possibly by alphaadrenergic activity. ${ }^{2}$ Whether patients susceptible to coronary artery spasm or to oesophageal spasm have a generalised sensitivity to alpha-adrenergic stimulation does not appear to have been adequately tested. Both these episodic phenomena can be induced pharmacologically by ergometrine which probably acts through the alpha-adrenergic system. $^{34}$ In normal patients ergometrine induces a rise in blood pressure ${ }^{5-7}$ and a slight diffuse narrowing of coronary artery calibre. ${ }^{78}$ The magnitude of the normal blood pressure and coronary artery responses to ergometrine could give an indication of generalised sensitivity to such stimulation.

There is little evidence about the blood pressure response to ergometrine in patients susceptible to coronary artery spasm. ${ }^{7}$ It is also not established whether there is in normal patients a general correlation between the rise in blood pressure and the severity of the diffuse narrowing of coronary arteries induced by ergometrine, though the absence of any such correlation is suggested by the data of one report. ${ }^{7}$ The pattern of diffuse narrowReceived for publication 21 July 1980 ing induced in different parts of the coronary artery tree by ergometrine in normal patients has been reported to be similar, ${ }^{8}$ but no information about the left main stem artery was included in that study.

We have accordingly measured, correlated, and compared the blood pressure and the diffuse coronary artery responses to ergometrine in patients with coronary artery spasm, in patients with oesophageal spasm, and in normal subjects.

\section{Methods}

The series consisted of 32 patients (19 men, 13 women, aged 30 to 65 years) investigated for possible coronary artery disease but found to have angiographically "normal" coronary arteries: 25 of these patients had completely normal angiographic appearances, four patients had minor irregularities of the lumen, three patients (one in group 2, two in group 3) had a single fixed narrowing of about 50 per cent. Patients were not treated with betablockers for more than five days, nor with nitrates for more than one day before investigation; atropine and nitrates were not given during the study. All patients gave informed consent in writing before cardiac catheterisation, it having been explained that they would at some time during the procedure be given an intravenous injection which might 
induce their pain. Isosorbide dinitrate solution was available for intravenous or intracoronary injection if necessary.

Arterial and coronary sinus blood samples were taken for measurements of lactate concentration at rest, after atrial pacing to maximum achievable ventricular rate, and five minutes after ergometrine injection. Systemic arterial blood pressure and electronically derived mean pressure were recorded through fluid filled catheters. Left ventriculography and coronary arteriography (Judkins technique) were performed.

Ergometrine $(500 \mu \mathrm{g})$ in each case was given by slow intravenous injection without the patient being aware of the time of its administration. Left and right coronary arteriograms, heart rate, and blood pressure measurements were performed before and five minutes after ergometrine injection. The arteriograms were filmed under constant geometric conditions. The left anterior oblique was selected for right coronary artery measurements and the right anterior oblique projection for left coronary artery measurements. All measurements were made at end-diastole. The angiograms were taken from a Sirecon 6 in intensifier (Siemens) filmed at 50 frames/s on Kodak CFA $35 \mathrm{~mm}$ film. Measurements were made from a screen image $6 \mathrm{ft}$ from a Vanguard XR 35 projector. The coronary artery diameter was measured at seven identified sites, left main stem, and proximal and more distal sites of right, left anterior descending, and circumflex coronary arteries (Fig.).
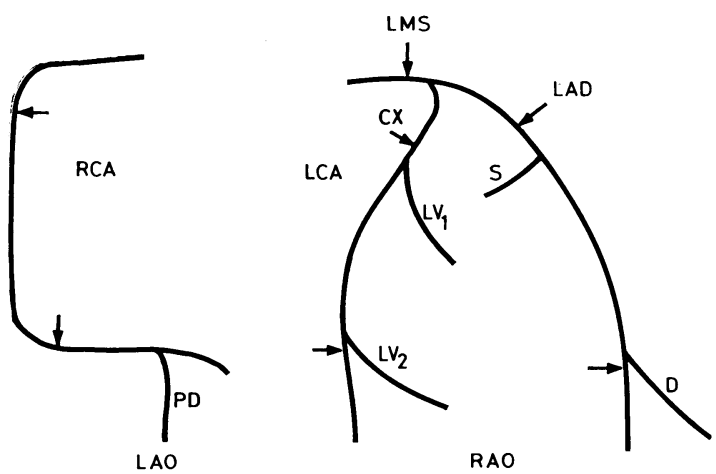

Fig. Seven sites (arrows) at which coronary artery narrowing was measured. LAO, left anterior oblique; $R A O$, right anterior oblique; $R C A$, right coronary artery; LCA, left coronary artery; $L M S$, left main stem; $L A D$, left anterior descending; $C X$, circumflex artery; $S, 1$ st septal; $D$, last diagonal; $L V_{1}$, 1 st left ventricular branch; $\mathrm{LV}_{2}$, last ventricular branch of circumflex; $P D$, posterior descending.
The series was divided into three groups. Group 1 consisted of five patients in whom ergometrine induced characteristic pain associated with severe spasm of otherwise angiographically completely normal coronary arteries. Group 2 consisted of 13 patients in whom ergometrine induced pain without any localised coronary artery spasm or diagnostic electrocardiographic or metabolic evidence of myocardial ischaemia. In these patients it was subsequently shown, with oesophageal manometry, that their pain was associated with oesophageal spasm. ${ }^{1}$ Group 3 consisted of 14 patients in whom ergometrine did not induce pain, coronary artery spasm, or electrocardiographic or metabolic evidence of myocardial ischaemia.

Data, given as mean \pm standard error, are compared within patients by paired t test and between groups by $t$ test, $p$ value $<0.05$ being taken as the limit of statistical significance.

\section{Results}

\section{BLOOD PRESSURE AND HEART RATE} RESPONSE

Ergometrine increased systolic, diastolic, and mean blood pressures in the series as a whole $(n=32)$ by $16 \cdot 8 \pm 2 \cdot 1$ per cent (range 0 to $52 \%$ ), $18.0 \pm 3 \cdot 2$ per cent (range -5 to $66 \%$ ), and $18.9 \pm 2.4$ per cent (range -4 to $67 \%$ ), respectively (Table 1 ). The increase in diastolic and mean blood pressures was slightly greater in group 1 than in groups 2 and 3 combined, but the difference reached significance only with respect to diastolic pressure. There was no correlation between the initial systolic, diastolic or mean pressure $(\mathrm{mmHg})$ and their response $(\%$ change) to ergometrine $(r=0.18,0.11,0.14$, respectively, in each case, $\mathrm{n}=32$ ). If the $500 \mu \mathrm{g}$ dose of ergometrine was normalised by expression relative to body weight there was no correlation between the normalised dose (range 5.4 to $10.4 \mu \mathrm{g} / \mathrm{kg}$ ) and the percentage increase in systolic, diastolic, or mean blood pressure in any of the groups, nor in the series as a whole $(r=0.09,0.05$, and 0.24 for systolic, diastolic, and mean blood pressures respectively, $n=32$ ).

The heart rate increased slightly in group 1 but showed no change in groups 2 or 3 (Table 1 ).

\section{CORONARY ARTERY RESPONSE}

Table 1 shows that the degree of diffuse coronary artery narrowing, averaged in each patient for the seven sites at which it was measured, was similar in groups 2 and 3 . In group 1 patients it has been measured in coronary arteries not affected by localised spasm, where possible; the numbers are small but the data provide no evidence that these 
Table 1 Coronary artery diffuse narrowing, blood pressure, and heart rate responses to ergometrine in patients with: coronary artery spasm (group 1), oesophageal spasm (group 2), and neither (group 3)

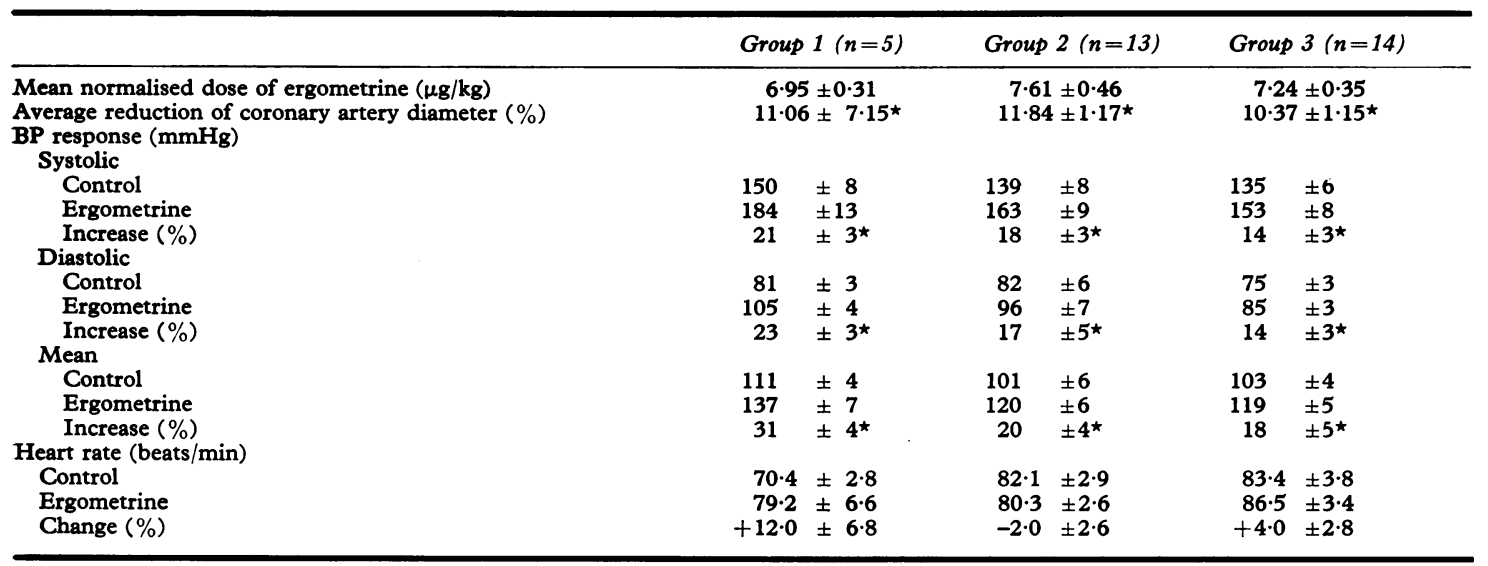

$\star_{\mathrm{p}}<0.05$ compared with pre-ergometrine control.

patients show a greater generalised response than patients not susceptible to coronary artery spasm (groups 2 and 3). Table 2 shows that in groups 2 and 3 combined, ergometrine induced diffuse narrowing to a similar extent at each of the measured sites except the left main stem which showed significantly less narrowing. Groups 2 and 3 did not differ from each other in this respect. The order in which coronary arteriograms were performed did not affect the extent of narrowing in the different arteries. There is no evidence that the percentage response was influenced by the initial calibre of the arteries, there being no correlation between the two $(r=0 \cdot 1, N S, n=27)$. When the dose of ergometrine was normalised for body weight there was no correlation between the dose and the extent of coronary artery narrowing in groups 2 and $3(r=0 \cdot 1, N S, n=27)$. Patients with minor coronary lesions had no greater response to ergometrine than those with angiographically completely normal vessels $(11 \cdot 4 \pm 2 \cdot 3 \%, n=7$, and $10.6 \pm 0.9 \%, n=20$, respectively). The average percentage reduction in coronary artery diameter did not differ significantly at different times of the day, being $10.8 \pm 1.3$ per cent $(n=15)$ in those studied in the morning, and $12 \cdot 8 \pm 1 \cdot 1$ per cent $(n=12)$ in those studied in the afternoon.

\section{CORRELATION OF CORONARY ARTERY AND BLOOD PRESSURE RESPONSE}

There was no correlation in groups 1,2 , or 3 , nor in all groups combined, between the ergometrineinduced narrowing of the coronary arteries (proximal, distal or combined) and the increase in blood pressure (systolic, diastolic, or mean).

\section{LACTATES}

In group 1 patients where ergometrine provoked coronary artery spasm, this was associated with myocardial lactate production in the three patients where time allowed blood samples to be taken before coronary angiography and urgent therapeutic reversal of spasm. In groups 2 and 3, ergometrine resulted in no significant change in arterial lactate concentration $(0.57 \pm 0.04 \mathrm{mmol} / 1$ before and $0.63 \pm 0.07 \mathrm{mmol} / \mathrm{l}$ after ergometrine, $\mathrm{n}=20$ ),

Table 2 Diffuse coronary artery narrowing (\%) with ergometrine compared at different sites (see Fig. 1) in 27 patients of groups 2 and 3

\begin{tabular}{|c|c|c|c|c|c|c|c|c|c|}
\hline \multirow[t]{2}{*}{$\begin{array}{l}\text { Left main } \\
\text { stem }\end{array}$} & \multicolumn{2}{|c|}{$\begin{array}{l}\text { Left anterior } \\
\text { descending }\end{array}$} & \multicolumn{2}{|l|}{$\begin{array}{l}\text { Circumflex } \\
\text { artery }\end{array}$} & \multicolumn{2}{|c|}{$\begin{array}{l}\text { Right coronary } \\
\text { artery }\end{array}$} & \multicolumn{2}{|c|}{$\begin{array}{l}\text { Combined (excluding } \\
\text { left main stem) }\end{array}$} & \multirow{2}{*}{$\begin{array}{l}\text { Total } \\
\text { (including } \\
\text { left main } \\
\text { stem) }\end{array}$} \\
\hline & Proximal & Distal & Proximal & Distal & Proximal & Distal & Proximal & Distal & \\
\hline $5 \cdot 46 \pm 1 \cdot 54^{\star}$ & $12 \cdot 05 \pm 2 \cdot 3$ & $11 \cdot 71 \pm 2 \cdot 42$ & $11 \cdot 69 \pm 2 \cdot 3$ & $12 \cdot 34 \pm 2 \cdot 4$ & $9 \cdot 98 \pm 2 \cdot 04$ & $13.54 \pm 2.04$ & $11 \cdot 50 \pm 1 \cdot 12$ & $13 \cdot 08 \pm 1 \cdot 37$ & $10 \cdot 83 \pm 0.86$ \\
\hline
\end{tabular}

${ }^{\star} \mathrm{p}<0.001$ compared with every other value. 
and no significant change of lactate extraction $(0.15 \pm 0.03 \mathrm{mmol} / 1$ before, $0.18 \pm 0.02 \mathrm{mmol} / 1$ after ergometrine) or extraction ratio $(25 \cdot 88 \pm 5 \cdot 79 \%$ before, $28.05 \pm 3.55 \%$ after ergometrine); in no case from groups 2 and 3 was the lactate extraction ratio less than 10 per cent.

\section{UNTOWARD EFFECTS}

Serious problems resulting from ergometrine have been described ${ }^{8-11}$ but none was encountered in this study. Feelings of lightheadedness and nausea were frequent. Vomiting was occasionally induced. Three patients complained of severe headache for several hours after the injection. No arrhythmias were observed in any of the patients with normal coronary arteries but in one of the five patients with coronary artery spasm multiple ventricular ectopics occurred after ergometrine in association with chest pain and ST segment elevation. Evidence of myocardial ischaemia resolved in each of these five patients within a few minutes of administering glyceryl trinitrate sublingually.

\section{Discussion}

Coronary artery spasm ${ }^{12}$ and oesophageal spasm may be mediated by alpha-adrenergic activity which is the probable basis of ergometrine's effect in patients with these susceptibilities. The underlying reason for these susceptibilities remains, however, unknown, and the study was undertaken to seek evidence of the possibility that they reflect a generalised increase in sensitivity to alphaadrenergic stimulation.

In group 1 patients susceptible to coronary artery spasm the rise in blood pressure induced by ergometrine was possibly higher than in other patients studied. Regional myocardial ischaemia, however, was presumably present in these patients at the time of measurement and this itself can lead to increased sympathetic drive as is in fact suggested by the greater beta-mediated increase in heart rate in these patients. Likewise, there was in this group no evidence for a particularly severe degree of diffuse narrowing of those coronary arteries not involved in localised spasm. This study therefore provides no good evidence that patients susceptible to coronary artery spasm have a generalised hypersensitivity to alpha-adrenergic stimulation. Similarly, in group 2 patients liable to oesophageal spasm, ergometrine induced no greater increase in blood pressure or diffuse coronary artery narrowing than in normal subjects, so that in these patients too there appeared to be no evidence of an underlying hypersensitivity to alpha-adrenergic stimulation.
The study also provides further evidence about the effects of ergometrine injection. The dose used represented a range of 5.4 to $10.4 \mu \mathrm{g} / \mathrm{kg}$ body weight. No dose response was apparent over this range either with respect to blood pressure or to diffuse coronary artery responses. This suggests that $500 \mu \mathrm{g}$ generally elicits maximum response, in accord with a report that diffuse coronary artery narrowing showed a dose response over a range of 100 to $400 \mu \mathrm{g}$ but not at higher doses of $800 \mu \mathrm{g} .^{8}$ Perhaps unexpectedly, there appeared to be no correlation between the magnitude of the diffuse coronary artery response and that of the blood pressure response. Furthermore, the magnitude of the response was in each case unrelated to the initial measurement before ergometrine.

The degree of coronary artery narrowing was shown not to be influenced by the order in which the two (right and left) coronary arteriograms were performed. There was no difference between the degree of diffuse coronary artery narrowing observed at the proximal and at the more distal (but still functionally "large") sites of the main branches, in accord with the only previous report on this point. ${ }^{8}$ There was, however, significantly less diffuse narrowing of the left main coronary artery, whose behaviour was not described in the earlier report. This could be attributable to reduced sensitivity of the alpha-receptor system, to relative paucity of smooth muscle, or to different orientation of muscle fibres in this vessel. A review of published reports ${ }^{7813-16}$ indicates that spasm of the left main stem is documented infrequently compared with spasm of the other major vessels, though this could simply be the result of the relatively smaller length of this vessel at risk.

Patients with variant angina tend to show a characteristic diurnal pattern in the occurrence of their attacks. ${ }^{17}$ We found no obvious difference in the diffuse coronary artery response to ergometrine in normal subjects at the different times of day.

The presence of minor coronary artery lesions did not influence the non-specific diffuse narrowing provoked by ergometrine. This is of interest in view of the implied relation between coronary artery spasm and underlying atheroma suggested by the high proportion of such patients with atheroma. ${ }^{16}$

The data for lactate levels across the coronary bed were in accord with previous data ${ }^{18}$ showing lactate "production" in the presence of ischaemia induced by coronary spasm. We observed no reduction of lactate extraction in any of the other patients, and, notably, no change in arterial lactate concentration which might have influenced lactate extraction. Ergometrine may limit the capacity of 
smaller arterioles to dilate ${ }^{19}$ in response to increased myocardial wall tension and energy requirements, and so predispose to myocardial ischaemia especially where the metabolic economic reserve is already impaired by associated disease. The lactate data, however, gave no evidence ${ }^{20}$ of ergometrineinduced myocardial ischaemia in any patient from groups 2 or 3 of the present study.

While this study gives further information about the effects of ergometrine in patients with and without coronary artery or oesophageal spasm, it provides no evidence for an underlying hypersensitivity of the alpha-adrenergic system in either syndrome.

We wish to acknowledge assistance from Dr R G Newcombe, Department of Medical Statistics, Welsh National School of Medicine, Heath Park, Cardiff.

\section{References}

1 Dart AM, Alban Davies H, Lowndes R, Dalal JJ, Ruttley MST, Henderson AH. Oesophageal spasm and "angina": diagnostic value of ergometrine provocation. Eur Heart $\mathcal{f} 1980$; 1: 91-5.

2 Yasue $H$, Touyama $M$, Kato $H$, Tanaka S, Akiyama F. Prinzmetal's variant form of angina as a manifestation of alpha-adrenergic receptor-mediated coronary artery spasm: documentation by coronary arteriography. Am Heart $\mathcal{F} 1976$; 91 : 148-55.

3 Innes IR. Identification of the smooth muscle excitatory receptors for ergot alkaloids. $\mathrm{Br} \mathcal{F}$ Pharmacol 1962; 19: 120-8.

4 Wassef MR, Lal H, Pleuvry BJ. The cardiovascular effect of ergometrine in the experimental animal in vivo and in vitro. $B r \mathcal{F}$ Anaesth $1974 ; 46: 473-8$.

5 Baillie TW. Vasopressor activity of ergometrine maleate in anaesthetized parturient women. $\mathrm{Br} \mathrm{Med}$ f 1963; i: 585-8.

6 Selwyn Crawford J. Vasopressor activity of ergometrine (letter). $\mathrm{Br} \mathrm{Med} \mathcal{F} 1963$; i: 1285.

7 Curry RC, Jr, Pepine CJ, Sabom MB, Feldman RL, Christie LG, Conti CR. Effects of ergonovine in patients with and without coronary artery disease. Circulation 1977; 56: 803-9.

8 Cipriano PR, Guthaner DF, Orlick AE, Ricci DR, Wexler L, Silverman JF. The effects of ergonovine maleate on coronary arterial size. Circulation 1979; 59: 82-9.
9 Browning DJ. Serious side effects of ergometrine and its use in routine obstetric practice. Med $\mathcal{F}$ Aust 1974; i: 957-9.

10 Cheng TO, Bashour T, Singh BK, Kelser GA. Myocardial infarction in the absence of coronary atherosclerosis: result of coronary spasm (?). $A m \mathcal{F}$ Cardiol 1972; 30: 680-2.

11 Cheng TO. Ergotrate in coronary artery spasm (letter). Circulation 1976; 53: 585-6.

12 Ricci DR, Orlick AE, Cipriano PR, Guthaner DF, Harrison DC. Altered adrenergic activity in coronary arterial spasm: insight into mechanism based on study of coronary hemodynamics and the electrocardiogram. Am f Cardiol 1979; 43: 1073-9.

13 Wiener L, Kasparian H, Duca P, et al. Spectrum of coronary arterial spasm. Clinical angiographic and myocardial metabolic experience in 29 cases. Am $\mathcal{F}$ Cardiol 1976; 38: 945-55.

14 Heupler FA Jr, Proudfit WL, Razavi M, Shirey EK, Greenstreet R, Sheldon WC. Ergonovine maleate provocative test for coronary arterial spasm. $A m \mathcal{F}$ Cardiol 1978; 41: 631-40.

15 Schroeder JS, Bolen JL, Quint RA, et al. Provocation of coronary spasm with ergonovine maleate. Am $\mathcal{F}$ Cardiol 1977; 40: 487-91.

16 Maseri A, Severi S, De Nes M, et al. "Variant" angina: one aspect of a continuous spectrum of vasospastic myocardial ischemia. Am $\mathcal{F}$ Cardiol 1978; 42: 1019-35.

17 Yasue H, Omote S, Takizawa A, Nagao M, Miwa K, Tanaka S. Circardian variation of exercise capacity in patients with Prinzmetal's variant angina: role of exercise induced coronary arterial spasm. Circulation 1979 ; 59: $938-48$.

18 Goldberg S, Lam W, Mudge G, et al. Coronary hemodynamic and myocardial metabolic alterations accompanying coronary spasm. Am f Cardiol 1979; 43: 481-7.

19 Orlick AE, Ricci DR, Cipriano PR, Guthaner DF, Harrison DC. Coronary hemodynamic effects of ergonovine maleate in human subjects. $A m \mathcal{F}$ Cardiol 1980; 45: 48-52.

20 Cohen LS, Elliott WC, Klein MD, Gorlin R. Coronary heart disease. Clinical, cinearteriographic and metabolic correlations. Am f Cardiol 1966; 17: $153-68$.

Requests for reprints to Professor A H Henderson, Department of Cardiology, Welsh National School of Medicine, Heath Park, Cardiff CF4 4XN. 